Banach space, by Mr. Garrett Birkhoff. (Abstract No. 40-11327-t.)

21. On monogenic extension of linear functionals, by $\mathrm{Mr}$. Garrett Birkhoff. (Abstract No. 40-11-328-t.)

22. Orthogonality in normed vector spaces, by Mr. Garrett Birkhoff. (Abstract No. 40-11-329-t.)

23. On a generalized tangent vector. Paper II, by Professor H. V. Craig. (Abstract No. 40-11-330-t.)

24. The number of trisecants of a space curve of order $m$ which meet an $i$-fold secant, by Dr. L. A. Dye. (Abstract No. 40-9300-t.)

25. On summation of derived series of the conjugate Fourier series. II, by Professor A. F. Moursund. (Abstract No. 40-9309-t.)

26. The Bloch constant $\mathfrak{A}$ for a schlicht function, by Mr. R. M. Robinson. (Abstract No. 40-11-331-t.)

27. Concerning curves of finite degree and local separating points, by Professor G. T. Whyburn. (Abstract No. 40-11-332-t.)

28. A decomposition theorem for continua, by Professor G. T. Whyburn. (Abstract No. 40-11-333-t.)

\author{
J. R. KLINE \\ Associate Secretary
}

\title{
THE MATHEMATICAL CONGRESS IN STOCKHOLM
}

The eighth Scandinavian mathematical congress was held at the University of Stockholm, from Tuesday to Saturday, August 14-18, 1934. The proceedings were opened Tuesday morning by Professor E. Phragmén, who was elected president of the Congress. About two hundred twenty-five persons had registered, including fifty family members. The arrangements of the organization committee and of the ladies' committee were well planned and superbly executed, and the efficient secretary, Mr. W. Odhnoff, was singled out for a toast. There was a reception supper dance in the Golden Room of the Town Hall on Tuesday evening, and a final banquet given by the Mittag-Leffler Institute at the summer restaurant "Hasselbacken" on Saturday evening. At the latter, Professor R. Nevanlinna extended the invitation of the Finnish mathematicians to 
hold the ninth congress at Helsingfors in 1938, which was accepted by acclamation. A monument was uncovered on the grave of Gösta and Signe Mittag-Leffler at Djursholm on Saturday afternoon. The ladies' program included excursions to the castle of Drottningholm with its interesting eighteenth century theatre, and to the new observatory at Saltsjöbaden.

The scientific meetings opened on Tuesday afternoon and continued until Saturday morning. The program contained forty-five papers. Those which follow were scheduled for fortyfive minutes: Graphical geometry, by Professor E. Hjelmslev; On the analytic representation of automorphic functions, by Professor P. Myrberg; A purely conceptual foundation of geometry, by Dr. H. Petrini; The latest development of the theory of almost periodic functions, by Professor Harald Bohr; On the harmonic measure of point sets and its applications to function theory, by Professor R. Nevanlinna; A method for the treatment of certain exponential equations and diophantine equations, by Dr. Th. Skolem; Quasi-analytic limit functions of rational functions, by Docent A. Beurling; Distribution functions and the Riemann zeta function, by Docent B. Jessen; On Laplace integrals, by Professor E. Hille; Function theoretical null sets, and the maximum principle for multiform analytic functions, by Docent G. Hössjer; On conformal mapping of "Überlagerungsflächen," by Dr. L. Ahlfors; On the defective values of a meromorphic function, by Mr. O. Frostman.

Einar Hille

YALE UNIVERSITY 